\title{
Effect of intravenous iron-dextran (Imferon) infusion on antigen induced monarticular arthritis in rabbits
}

\author{
C N Kind, A Blackham, C J Morris
}

\begin{abstract}
The effect of intravenously infused irondextran (Imferon) on the progression of antigen induced monarticular arthritis in rabbits was studied. A rapid deposition of iron and apoferritin in the synovia of arthritic joints occurred after infusion of iron-dextran during either the acute or chronic phases of the disease. This coincided with the appearance of catalytic (bleomycin reactive) iron in the synovial fluid. There was no evidence, however, for an exacerbation of the antigen induced arthritis as a result of the irondextran, and synovial and bleomycin reactive iron concentrations decreased with time after administration, indicating a redistribution of the synovial iron load. Thus although intravenously infused iron-dextran appears to 'prime' the rabbit arthritic joint transiently with the potential for iron stimulated oxygen free radical damage, other factors may determine its occurrence.
\end{abstract}

(Ann Rheum Dis 1992; 51: 1237-1241)

Oxygen containing free radicals generated by inflammatory cells during the respiratory burst may, in the presence of catalytic amounts of a transition metal such as iron, react to form the hydroxyl ion, a potentially tissue damaging species. ${ }^{1}$ Accordingly, iron may have a role in the pathogenesis of rheumatoid arthritis, where infiltration of activated neutrophils and other cells into the diseased joint is often accompanied by an increased deposition of iron. ${ }^{2}$ The susceptibility of the inflamed rheumatoid joint tissue to periods of ischaemia followed by reperfusion also provides an environment capable of initiating the formation of oxygen free radicals. ${ }^{34}$

A further indication of the part played by iron in rheumatoid arthritis is seen in patients given intravenous iron-dextran (Imferon) for treatment of coexisting iron deficiency anaemia. A high proportion of these subjects have a transient synovial flare, usually confined to previously affected joints and developing within three days of the iron infusion. Although the mechanism of this reaction is unknown, the possibility exists that a local increase in iron concentrations results in the stimulation of oxygen radical mediated tissue damage. ${ }^{5}$

Little is known of the fate of iron-dextran in the rheumatoid joint, particularly with respect to its influence on disease processes. The effect of iron-dextran on inflammatory synovitis was therefore investigated using an experimentally induced rabbit model of monarticular arthritis ${ }^{6}$ which, in terms of histological appearance, gross pathology, and drug responsiveness, closely resembles the human rheumatoid disease. The principal aims of the study were $(a)$ to establish the disposition of the iron load within the diseased joint and $(b)$ to determine the effect of intravenous iron-dextran, infused during the acute and chronic phases of the arthritis, on the progression and extent of the inflammatory reaction.

\section{Materials and methods}

\section{INDUCTION OF MONARTICULAR ARTHRITIS}

Monarticular arthritis was induced in 28 ovalbumin sensitised Old English rabbits (mixed sexes, weight range $2-3 \mathrm{~kg}$ ) by intra-articular injection of ovalbumin into the right knee joint. ${ }^{6}$ The left knee of each rabbit was injected with sterile saline to act as a control.

ADMINISTRATION OF IRON-DEXTRAN

Iron-dextran (equivalent to $50 \mathrm{mg} \mathrm{Fe} / \mathrm{kg}$ body weight) or saline was administered into a marginal ear vein of each animal by slow infusion either three days (acute phase, experiment $1 ; 18$ animals) or 16 days (chronic phase,
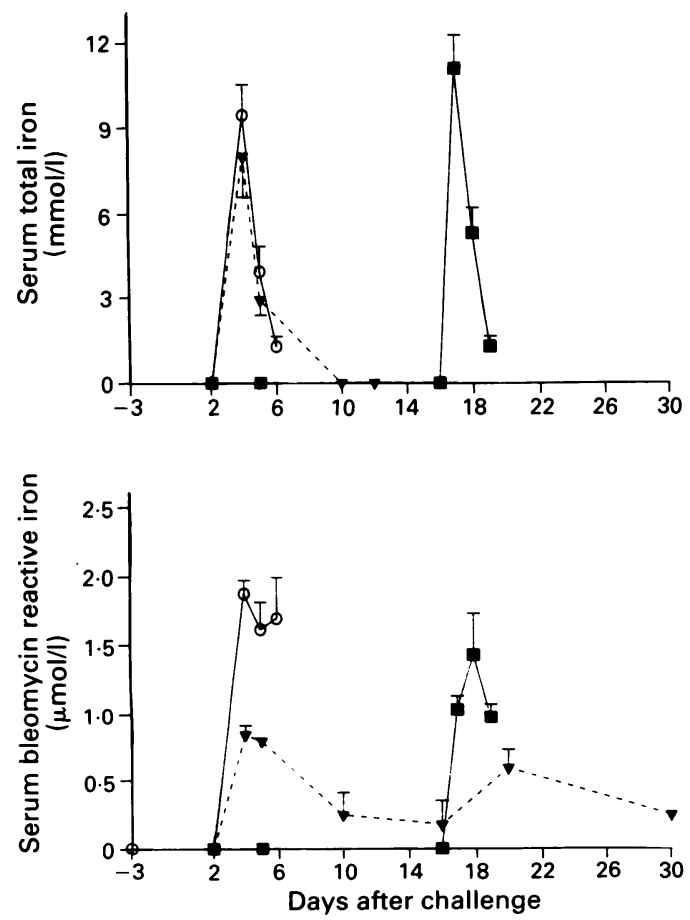

Figure 1 Concentrations of total and bleomycin reactive iron in the serum of arthritic rabbits after intravenous infusion of iron-dextran. (O) Group mean expt $1 A ;(\nabla)$ group mean expt $1 B ;(\square)$ group mean expt 2. Bars $=S E M$. 


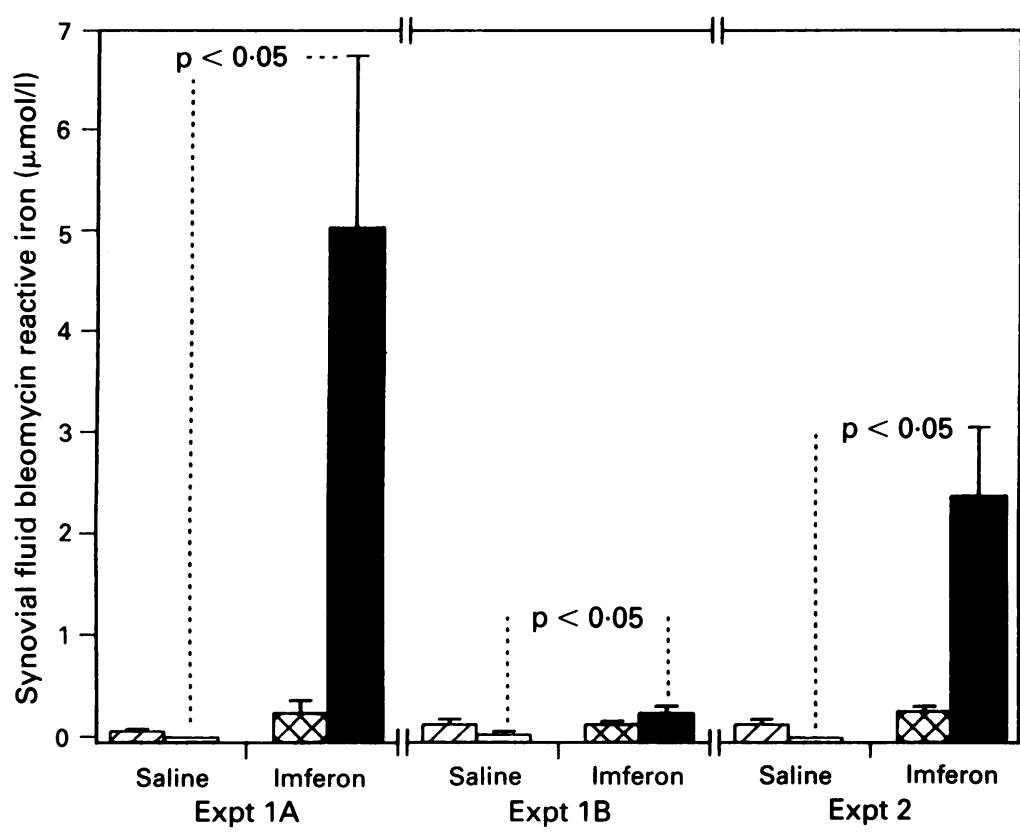

Figure 2 Concentrations of bleomycin reactive iron in the synovial fluid of rabbits after intravenous infusion of iron-dextran (Imferon) (cross hatch bars=left (control) knee; filled bars = right (arthritic) knee), or saline (single-hatch bars=left (control) knee; open bars = right (arthritic) knee). Bars $=$ SEM.

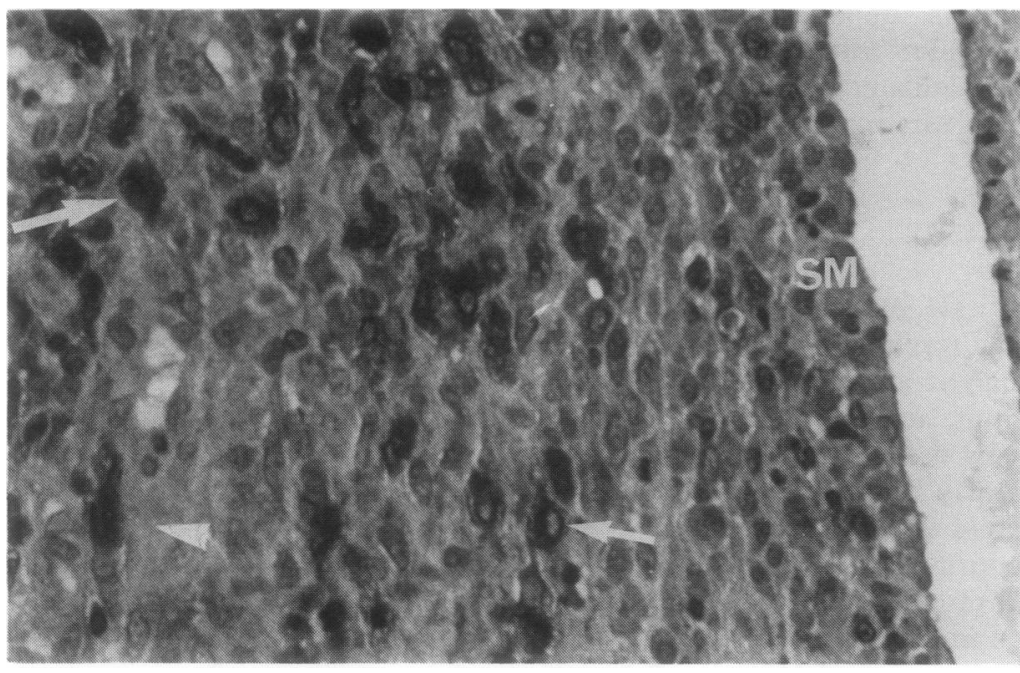

Figure 3 Section of synovial tissue from the arthritic knee of a rabbit, six days after intraarticular antigen challenge and three days after intravenous infusion of iron-dextran. The section was stained for apoferritin (peroxidase) and counterstained with haematoxylin.

$S M$ denotes the synovial membrane; arrows indicate intracellular and arrowhead extracellular deposits of apoferritin. experiment $2 ; 10$ animals) after challenge. In experiment 1 , five iron-dextran and five saline treated rabbits were killed three days after infusion (day 6; group $\mathrm{A}$ ). The remaining animals (four treated with iron-dextran and four with saline) were killed 27 days after infusion (day 30; group B). In experiment 2, all animals (five iron-dextran and five saline treated) were killed three days after the infusion (day 19). Heparinised blood samples were taken from the marginal ear vein of all animals at intervals during the course of the study. Plasma prepared from these was stored at $4^{\circ} \mathrm{C}$ or $-40^{\circ} \mathrm{C}$ before analysis.

\section{MEASUREMENTS}

Progression of the arthritic reaction was followed in each rabbit by measuring the difference between control and arthritic knee joint diameters and mobility at intervals over the course of the experiment (that is, from two days before intra-articular challenge until the animal was killed). Plasma acid glycoprotein concentration was monitored over a similar time course to assess the acute phase response.

Immediately after killing, the knee joints of each rabbit were dissected and examined macroscopically for evidence of pathological change. Parameters assessed included: synovial hyperplasia, petechiae, and vascularisation; synovial fluid effusion, viscosity, and solid inclusions; bone/cartilage erosion, pitting, periarticular fibrosis, and new bone formation. ${ }^{6}$ Each parameter was scored according to the degree of change using a grading from 0 (normal) to 3 (grossly abnormal). The maximum score possible for each joint was 30 . Synovial fluid from each joint was collected into separate containers and made up to $1.5 \mathrm{ml}$ using joint washings (performed using iron free heparinised saline). These were centrifuged and the supernatant removed and stored at $4^{\circ} \mathrm{C}$ before biochemical analysis. The remaining pellet was resuspended in rabbit plasma and the cell contents counted.

Sections of synovia were removed from the joint, fixed in buffered formalin, processed, and stained with haematoxylin and eosin for general morphological examination. The degree of synovial iron deposition was assessed visually from Perls' stained sections and scored using a

Distribution of iron in the synovia of rabbits after intravenous infusion of iron-dextran or saline. Results are expressed as the mean number of Perls' positive cells and the overall degree of staining in sections from each animal

\begin{tabular}{|c|c|c|c|c|c|c|c|c|}
\hline & \multicolumn{4}{|c|}{ Saline controls } & \multicolumn{4}{|c|}{ Treated with iron-dextran } \\
\hline & \multicolumn{2}{|l|}{ Left joint } & \multicolumn{2}{|l|}{ Right joint } & \multicolumn{2}{|l|}{ Left joint } & \multicolumn{2}{|l|}{ Right joint } \\
\hline & $\begin{array}{l}\text { Mean (SD) } \\
\text { No of cells: }\end{array}$ & $\begin{array}{l}\text { Mean (range) } \\
\text { histological scoret }\end{array}$ & $\begin{array}{l}\text { Mean (SD) } \\
\text { No of cells: }\end{array}$ & $\begin{array}{l}\text { Mean (range) } \\
\text { histological scoret }\end{array}$ & $\begin{array}{l}\text { Mean (SD) } \\
\text { No of cells* }\end{array}$ & $\begin{array}{l}\text { Mean (range) } \\
\text { histological scoret }\end{array}$ & $\begin{array}{l}\text { Mean (SD) } \\
\text { No of cells* }\end{array}$ & $\begin{array}{l}\text { Mean (range) } \\
\text { histological scoref }\end{array}$ \\
\hline $\begin{array}{ll}\text { Experiment } & 1 \mathrm{~A} \\
\text { Experiment } & 1 \mathrm{~B} \\
\text { Experiment } & 2\end{array}$ & $\begin{array}{ll}1 \cdot 2 & (1 \cdot 6) \\
6 \cdot 2 & (6 \cdot 8) \\
0.8 & (1.5)\end{array}$ & $\begin{array}{l}0(0-1) \\
1(0-1) \\
0(0)\end{array}$ & $\begin{array}{l}0.9(1.5) \\
12.4(18.5) \\
1.1(1.1)\end{array}$ & $\begin{array}{l}0(0-1) \\
1(1) \\
0(0-1)\end{array}$ & $\begin{array}{l}30.0(20.9) \\
51.5(36.4) \\
32.4(35.5)\end{array}$ & $\begin{array}{l}2(1-3) \\
2(0-3) \\
1(0-4)\end{array}$ & $\begin{array}{l}48 \cdot 0(20 \cdot 6) \\
24 \cdot 1(4 \cdot 4) \\
83 \cdot 0(15 \cdot 0)\end{array}$ & $\begin{array}{ll}4 & (2-4) \\
3 & (2-3) \\
3 & (3-4)\end{array}$ \\
\hline Statistical results & $\begin{array}{l}\text { B } \\
\text { C NS }\end{array}$ & & $\begin{array}{l}\text { B } \\
\text { C NS }\end{array}$ & & $\begin{array}{l}\text { B NS } \\
\text { C NS }\end{array}$ & & $\begin{array}{l}\mathbf{A}^{* * * *} \\
\mathbf{B}^{*} \\
C^{* * *}\end{array}$ & \\
\hline
\end{tabular}

"Cell counts: Iron deposition in synovial sections was estimated by counting the number of Perls' positive cells in random fields of view ( $\times 160$ constant magnification). †Histological score: $0=$ absent; $1=$ minimal; $2=$ small; 3 =moderate; and $4=$ heavy. p $<0.001$. 
grading system from 0 (absent) to 4 (heavy deposition). The occurrence of Perls' positive cells in each tissue section was determined by counting fields chosen at random, viewed at constant magnification $(\times 160) .{ }^{7}$ Selected synovia were stained for apoferritin using a primary antibody specific to the rabbit protein and a secondary antibody conjugated to horseradish peroxidase.
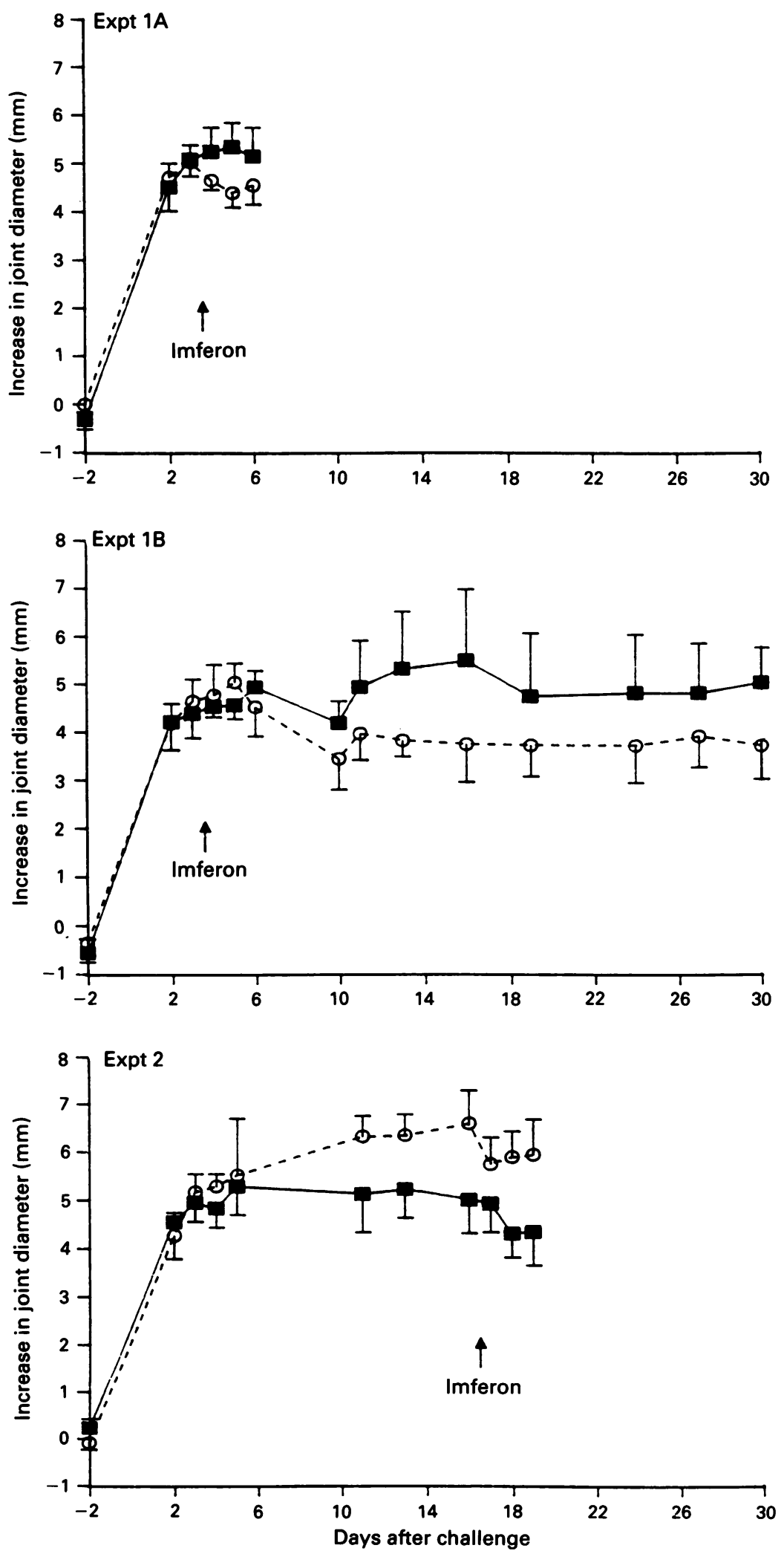

Figure 4 Change in knee joint diameter of rabbits after intra-articular antigen challenge and in response to intravenous infusion of iron-dextran (Imferon) ( $\square$ ) or saline (O). Data are mean of challenged minus control joint. Bars=SEM.
Plasma and synovial fluid samples were analysed for bleomycin reactive iron using a method based on that of Gutteridge $e t a l^{8}$ and for diene conjugates according to the method described by Lunec et al. ${ }^{9}$ Serum total iron concentrations were determined by atomic absorption spectrometry using a Perkin-Elmer Model 703 instrument.

\section{STATISTICS}

Where appropriate, the data obtained were analysed for statistical significance using Student's $t$ test in conjunction with analysis of variance.

\section{Results}

EFFECT OF IRON-DEXTRAN ON IRON DISPOSITION Infusion of iron-dextran into rabbits either three or 16 days after induction of the arthritic reaction resulted in the transient appearance of catalytic iron (that is, the fraction of iron detected by the bleomycin reaction) in the plasma within 48 hours of the infusion (fig 1). This coincided with increases in plasma total iron caused by the dose of iron-dextran. Catalytic iron was also present in increased amounts in the synovial fluid of rabbits treated with irondextran at the time of killing (fig 2). The highest concentrations occurred in the arthritic joints, though distinct increases were also measured in the contralateral saline injected joint. Concentrations were considerably reduced in samples taken 27 days after the infusion of iron-dextran (experiment 1B) compared with those taken three days afterwards (experiment $1 B v$ experiment $1 \mathrm{~A} ; \mathrm{p}<0.05$ ).

Moderate to heavy cellular deposition of Perls' positive iron was present in the arthritic synovia of rabbits treated with iron-dextran (table). Control joint synovia of these animals also contained marked iron deposition. The distribution of iron in tissues was similar in arthritic and control synovia and was predominantly localised within the cytoplasm of macrophage-like cells in the vascular layer of the synovial membrane. A number of other cells in deeper tissue contained dense granular type staining and occasional areas of faintly stained cells were also present, usually in more superficial layers. As with catalytic iron in synovial fluid, a reduction in tissue iron deposition was apparent with the length of time after infusion of iron-dextran. Although the rabbits infused 16 days after intra-articular challenge (experiment 2) showed a significantly greater number of iron containing cells compared with those infused three days after challenge, the overall amount of deposition in individual cells was reduced.

Rabbits infused with saline showed little detectable iron deposition in either arthritic or control joint synovia at the time of killing and plasma and synovial fluid concentrations of catalytic iron were correspondingly low or absent.

Intense apoferritin specific staining was apparent within macrophage-like cells in all layers of the arthritic synovia of animals infused with iron-dextran or saline examined six days 
after challenge (see fig 3), though the extent of apoferritin production was clearly greatest in the group treated with iron-dextran. Extracellular deposits were also visible within the tissue mass, often in large amounts. In comparison, the synovia of rabbits examined 19 days after challenge contained noticeably less apoferritin, though again, concentrations were greater in animals infused with iron-dextran. The control joint synovia of rabbits infused with
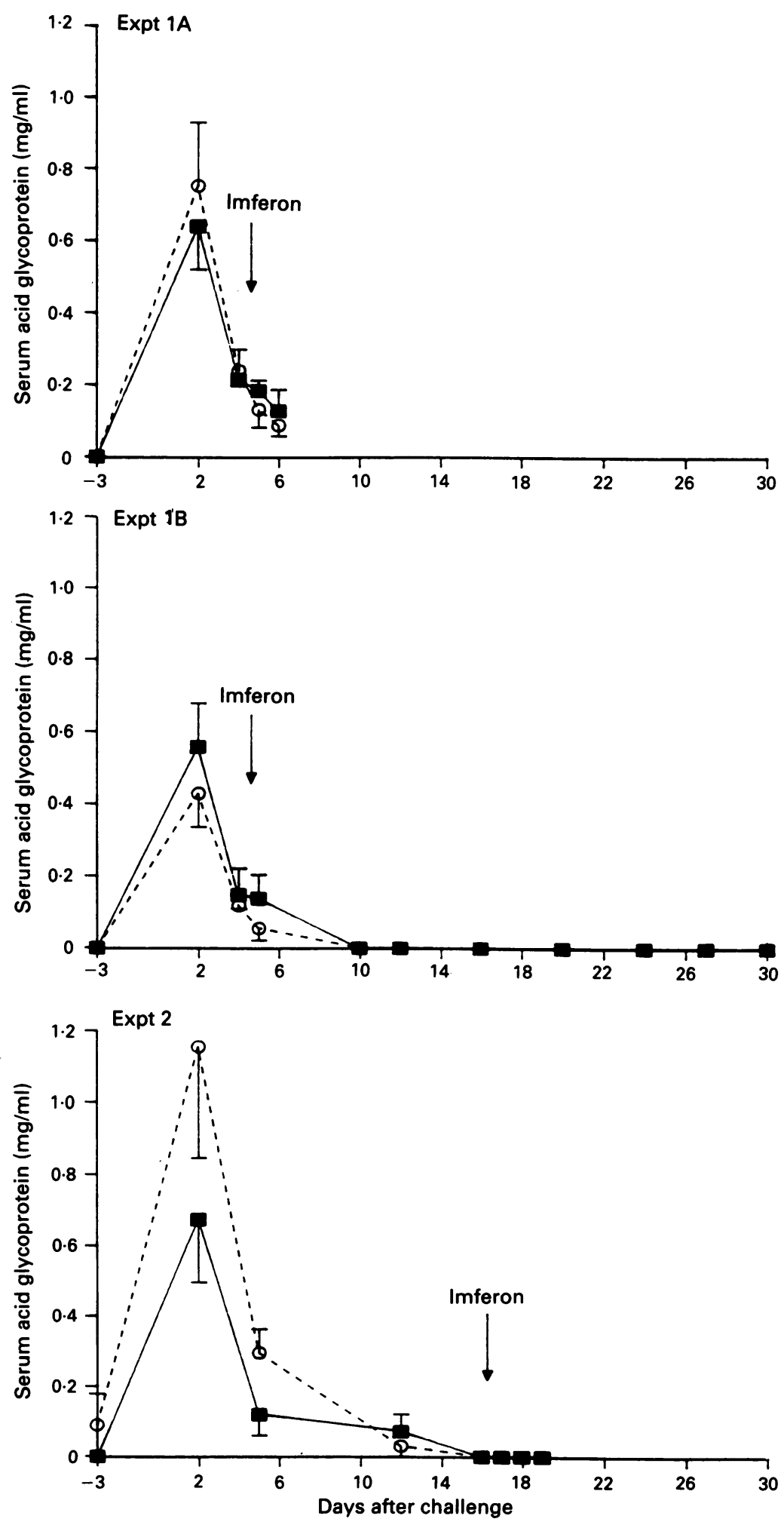

Figure 5 Serum acid glycoprotein concentrations in rabbits after intra-articular antigen challenge and in response to intravenous infusion of iron-dextran (Imferon) ( $\square$ ) or saline $(O)$. Data are group mean. Bars $=S E M$. iron-dextran also contained substantial apoferritin deposition, but this was invariably less than in the corresponding arthritic joint. Infusion of iron-dextran during the chronic phase of the induced synovitis (experiment 2) produced a lower apoferritin response in contrast to the acute phase infusion and numerous unstained cells were found. Once again, however, concentrations were greater than those present in animals infused with saline.

\section{EFFECT OF IRON-DEXTRAN ON DISEASE} PROGRESSION

All animals showed a marked monarticular synovitis within 48 hours of intra-articular challenge, as indicated by acute swelling (fig 4) and reduced mobility (data not shown) of the right knee. This was accompanied by a transient increase in serum acid glycoprotein concentrations, confirming the induction of an acute phase response (fig 5). The chronic progression of the disease was illustrated by the continued changes in joint diameter and mobility over the study period and was essentially similar to that observed previously. ${ }^{6}$

Examination of the joints at necropsy showed hyperplasia and inflammatory cell infiltration of the arthritic synovia, with erosion and pitting of the underlying articular cartilage and periarticular fibrosis. The associated synovial fluid contained high numbers of inflammatory cells, though numbers of polynuclear and mononuclear cells were lower in the animals treated with iron-dextran (not statistically significant). The overall extent of the disease tended to increase with the number of days elapsed after challenge (fig 6).

Iron-dextran had no consistent effect on the progression or extent of the induced arthritis when administered during either acute or chronic phases of the disease and there was no significant difference between the groups infused with iron-dextran or saline with respect to joint swelling, pathological change, or plasma acid glycoprotein concentration. Furthermore, no significant difference in plasma or synovial fluid concentrations of diene conjugates was found between rabbits treated with iron-dextran or saline during the study, indicating that lipid peroxidation was not increased by this treatment (results not shown).

\section{Discussion}

Intra-articular injection of antigen into sensitised rabbits produced an inflammatory reaction over the anticipated time course as shown by swelling and lack of mobility in the affected joint. Infusion of iron-dextran at the peak of the acute response (three days) or when the chronic phase was well established (16 days) caused a rapid deposition of iron into inflamed and control joints three days later. It is not clear from our results whether the iron arrived in the joint by passing through permeabilised blood vessels as complexed iron-dextran, was carried in by transferrin, or transported by infiltrating macrophages. In those rabbits infused with saline, iron was present only in the arthritic 


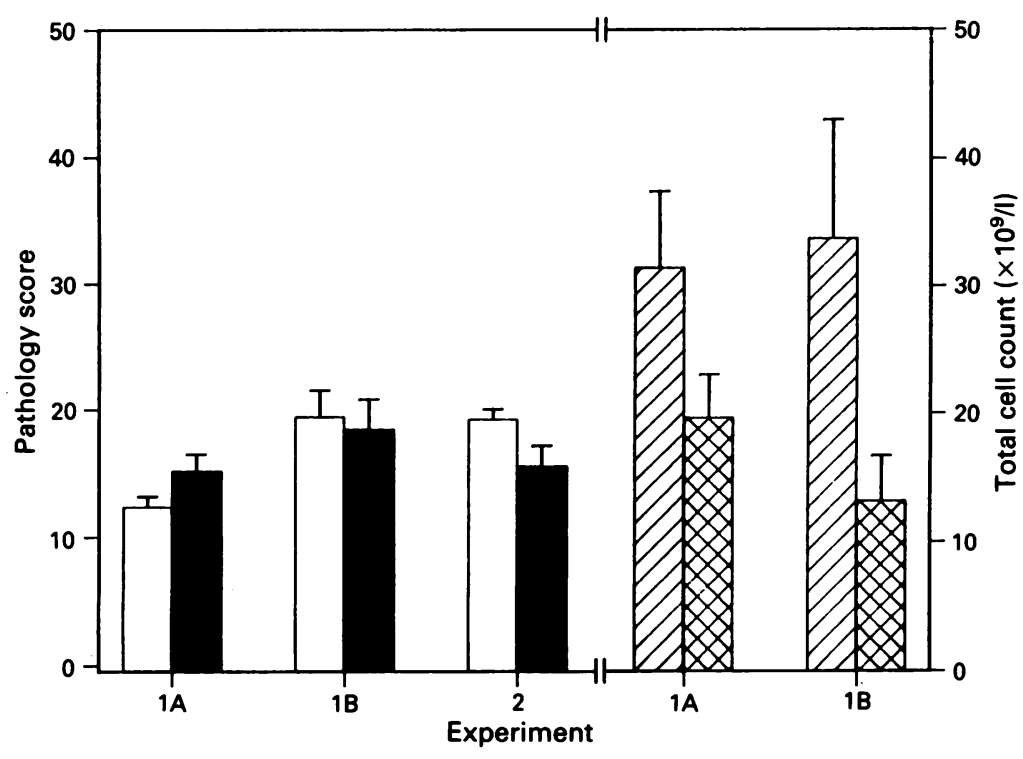

Figure 6 Gross pathology score and synovial fluid cell count of rabbit arthritic knee joints after intravenous infusion of iron-dextran (filled bars=mean pathology score; cross hatched bars = mean cell count) or saline (open bars=mean pathology score; single hatched bars=mean cell count). Bars=SEM. have shown a positive correlation between catalytic iron and disease activity in rheumatoid patients, ${ }^{16}$ and data presented by Winyard $e t$ $a l, 5$ on a single patient infused with irondextran (approximately $12 \mathrm{mg} \mathrm{Fe} / \mathrm{kg}$ ), appear to link treatment with the subsequent synovial flare and evidence of oxidant stress. In this study, intravenous infusion of iron-dextran, equivalent to a loading of $50 \mathrm{mg} \mathrm{Fe} / \mathrm{kg}$ body weight, was shown to prime the rabbit arthritic joints with comparable concentrations of catalytic iron in the acute and chronic phases of the disease. It was surprising therefore to find no evidence of exacerbation of the inflammatory response induced by iron-dextran, particularly in view of the similarities between this model and rheumatoid arthritis. A number of possible explanations could account for this including: (a) the presence of protective factors-for example, the acute phase reactant caeruloplasmin, which has powerful antioxidant and free radical scavenging properties; $(b)$ the supply of superoxide and hydrogen peroxide substrates was limiting at the time when catalytic iron was available; or $(c)$ that some other component of iron-dextran, such as the dextran moiety, is responsible for the flare seen in rheumatoid patients. result of intra-articular haemorrhaging.

The increased synovial iron load in rabbits infused with iron-dextran was associated with stimulated apoferritin synthesis above that caused by inflammation. Ferritin plays a pivotal part in iron homeostasis within the cell ${ }^{10}$ and is an important factor in protection of the intracellular environment from the catalytic effects of 'free' iron. Although ferritin bound iron may itself be made available to promote oxygen radical reactions in inflammatory diseases, ${ }^{11}$ this apears to be dependent on the degree of iron loading within the protein shell. ${ }^{12}$ The enhanced synthesis of apoferritin by the arthritic synovium may therefore be protective insofar as it tends to reduce the iron to apoferritin ratio.

Data from experiment $1 \mathrm{~B}$ suggest that the intracellular iron deposits were substantially redistributed following the initial uptake of the load derived from iron-dextran and that this coincided with a decrease in apoferritin levels. Ferritin is increasingly implicated in the extracellular transport of iron, ${ }^{13}$ and may constitute a major mechanism for the movement of iron between the reticuloendothelial system and other tissues of the body. Indeed, the extracellular apoferritin deposits observed in this study are consistent with such a process. The movement of iron derived from iron-dextran out of the joint has important consequences with respect to its potential toxicity. This is illustrated by the reduction of catalytic iron concentrations in synovial fluid with time after infusion of iron-dextran, thereby reducing the possibility of iron promoted formation of hydroxyl radicals.

Iron has been implicated as a promoter of inflammatory reactions in a variety of experimental animal models. ${ }^{714}$ Clinical studies
1 Halliwell B, Gutteridge J M C. Oxygen toxicity, oxygen radicals, transition metals and disease. Biochem $\mathcal{F} 1984$ 219: $1-14$

2 Blake D R, Hall N D, Bacon P A, Dieppe P A, Halliwell B, Gutteridge J M C. Hypothesis: the importance of iron in rheumatoid disease. Lancet 1981; ii: 1142-4.

3 Levick J R. Hypoxia and acidosis in chronic inflammatory pressure. I Rheumatol 1990; 17: 579-82.

4 Merry P, Grootveld M, Lunec J, Blake D R. Oxidative damage to lipids within the inflamed human joint provides damage to lipids within the inflamed human joint provides Am 7 Clin Nutr 1991; 53: 362S-9S.

5 Winyard P G, Blake D R, Chirico S, et al. Mechanism of exacerbation of rheumatoid arthritis by total-dose irondextran infusion: in vivo demonstration of iron promoted oxidant stress. Lancet 1987; i: 69-72. role of prostaglandins in rabbit monoarticular arthritis. $B$ f Pharmacol 1974; 51: 35-44.

7 Morris C J, Blake D R, Hewitt S D, Lunec J. Macrophage ferritin and iron deposition in the rat air-pouch model of inflammatory synovitis. Ann Rheum Dis 1987; 46: 334-8.

inflammatory synovitis. Ann Rheum Dis 1987; 46: 334-8.
8 Gutteridge J M C, Rowley D A, Halliwell B. Superoxidedependent formation of hydroxyl radicals in the presence of iron salts. Biochem $\mathcal{F}$ 1981; 199: 263-5.

9 Lunec J, Halloran S D, White A G, Dormandy T L. Free radical oxidation (peroxidation) products in serum and synovial fluid of rheumatoid arthritis. $\mathcal{F}$ Rheumatol $1981 ; 8$ 233-45.

10 Mattia E, Renswoude J V. The pivotal role of ferritin in cellular iron homeostasis. Bioessays 1988; 8: 107-11

11 Biemond P, Swaak A J G, Van Eijk H G, Koster J F. Superoxide dependent iron release from ferritin in inflammatory diseases. Free Radic Biol Med 1988; 4: 195-8.

12 Bannister J V, Bannister W H, Thornalley P J. The effect of ferritin iron loading on hydroxyl radical production. Life Chem Rep 1984; 2 (suppl): 64-72.

13 Jin Y, Crichton R R. Iron transfer from ferritin to transferrin: effect of serum factors. FEBS Lett 1987; 215: 41-6.

14 Blake D R, Hall N D, Bacon P A, Dieppe P A, Halliwell B, Gutteridge J M C. Effect of a specific iron chelating agent on animal models of inflammation. Ann Rheum Dis 1983; 42: 89-93.

15 Andrews F J, Morris C J, Lewis E J, Blake D R. Effect of nutritional iron deficiency on acute and chronic inflammation. Ann Rheum Dis 1987; 46: 859-65.

16 Rowley D A, Gutteridge J M C, Blake D R, Farr M Thiobarbituric acid-reactive material and catalytic iron salts in synovial fluid from rheumatoid patients. Clin Sci 1984 66: 691-5. arthritis; relation to vascular supply and dynamic effusion

6 Blackham A, Farmer J B, Radziwonik H, Westwick J. The Halliwell B. Lipid peroxidation in rheumatoid arthritis. 